\title{
Energy value of unfermented dried grape pomace as substitute of alfalfa hay in diets for growing lambs
}

\author{
José F. Calderón-Cortés, Víctor M. González-Vizcarra, Yuridia Pétriz-Celaya, \\ Lourdes C. Pujol, Alberto Barreras, Alejandro Plascencia*
}

\begin{abstract}
The energy value of unfermented dried grape pomace (DGP) was evaluated in an $84 \mathrm{~d}$ feeding trial on 16 Pelibuey $\times$ Dorper lambs $(17.8 \pm 2.0 \mathrm{~kg})$. The control diet contained $90 \%$ mature alfalfa hay and $10 \%$ concentrates. Treatments consisted in the replacement (DM basis) of alfalfa hay by DGP at 0,10, 20 or 30\%. Lambs were blocked by weight and assigned individually to pens. Increasing DGP level in diet tended $(P=0.06)$ to decrease daily gain and linearly increased $(P=0.04)$ dry matter intake (DMI); thus, feed efficiency, dietary energy, and observed-to-expected diet NE were linearly decreased $(P<0.01)$, increasing linearly $(P<0.01)$ observed-to-expected DMI coefficient as DGP level was increased in the diet. There were no effects of treatments on carcass characteristics. Using the replacement technique, the energy value of DGP were $0.80,0.75$ and $0.67 \mathrm{Mcal} \mathrm{EN}_{\mathrm{m}} / \mathrm{kg} \mathrm{DM}$, for 10, 20 and 30\% of inclusion, respectively. It is concluded that the estimated NE of DGP at $10 \%$ inclusion level in the diet is very similar to the NE value assigned by the NRC (2007) for the fermented DGP. Increasing the inclusion of DGP levels beyond $10 \%$ decreases its energy value, maybe due to the negative associative effects of chemical compounds (such as phenols) naturally contained in DGP.

Key words: wine industry by-product, efficiency, energy value, carcass, ruminants.
\end{abstract}

\section{INTRODUCTION}

Viticulture is an important industry in Baja California, Mexico, and a large proportion of their organic by-products are fresh grape pomace (Bustamante et al 2008). Generally, grape pomace is constituted by stalks, seeds, skin and pulp in similar proportions, and dried grape pomace (DGP) is characterised by being a source of high fiber content with moderated concentration of $\mathrm{CP}$ and lipids, rich in organic acids as tannins and phenols (Nistor et al 2014). Based on fiber and protein concentrations, grape pomace is similar to mature alfalfa hay which is a common forage source for growing lambs. However, grape pomace is mainly considered as a waste product, being commonly collected and eventually used as soil improver. Some studies on the use of grape pomace as an ingredient for ruminant rations reported poor results on animal performance (Manterola et al 1997, Nistor et al 2016) and those results have been associated to the type of DGP, because DGP commonly used was a by-product of the alcoholic fermentation, and therefore it was low in sugars and energy value. The unfermented by-products of viticulture have a greater concentration of sugars, and theoretically more energy concentration (Baumgärtel et al 2007), however, they maintain higher concentrations of the original compounds such as tannins and phenols (Xu et al 2016), which may represent negative associative effects with other components of the diet that could affect the feeding value. Therefore, it is possible that the expected feeding value of GP could

Accepted: 02.11.2017.

Instituto de Investigaciones en Ciencias Veterinarias, Universidad Autónoma de Baja California, Baja California, México.

*Corresponding author: A Plascencia; aplas_99@yahoo.com, alejandro. plascencia@uabc.edu.mx be decreased as its inclusion increases in the diet. To our knowledge, there is no information available regarding the influence of unfermented dried grape pomace (DGP) inclusion level in partial replacement of forage in diets for growing lambs on the performance, dietary energy and carcass characteristics. Therefore, the objective of this trial was to determine the energy value of unfermented DGP included at different levels as a substitute of mature alfalfa hay in diets for growing lambs.

\section{MATERIAL AND METHODS}

Sixteen Pelibuey $\times$ Dorper lambs (initial weight at start of experiment $=17.8 \pm 2.0 \mathrm{~kg}$ ) were allocated (four lambs/treatment) to indoor facilities in individual pens of $3.4 \mathrm{~m}^{2}$ with automatic waterers and $0.50 \mathrm{~m}$ fence-line feed bunks. Before the start the experiment, lambs had a 14 days adaptation period to the basal diet (diet without dried grape pomace; table 1) and the facilities. The animals were also treated for internal parasites (Ivermectin, Vetoquinol, México), received injections of vitamins A, D, E (Synt-ADE, Fort Dodge, Animal Health, México), and were given ear tags. Treatments consisted of replacement (DM basis) of alfalfa hay in the basal diet by DGP at $0,10,20$ or $30 \%$. The grape pomace, obtained from red grape after the juice was extracted by crushing and pressing, was brought from a local viticulture. The material was first conveyed over a screen to separate liquids and solids. Solids were then spread over a concrete surface and allowed to air-dry. The final dried material was carefully mixed, grounded and sampled before it was incorporated to diets. The alfalfa hay used was obtained from a batch obtained from the same cut-harvest which was produced in Mexicali valley. Both, alfalfa hay and DGP were ground in a hammer mill (Bear Cat \#1A-S, Westerns Land and 
Roller Co., Hastings, NE, USA) with a $7.62 \mathrm{~cm}$ screen, before adding it to the complete mixed diet. Lambs were allowed ad libitum access to dietary treatments. Daily feed allotments to each pen were adjusted to allow minimal feed refusals ( $\sim 50 \mathrm{~g} / \mathrm{kg}$ of feed offered). The amounts of feed offered and refused were weighed daily. Lambs were provided fresh feed daily at 08:00 and 14:00 h in a 30:70 proportion (as fed basis). Refusals were collected and weighed prior to the morning feeding and feed intake was determined daily. The experiment lasted 84 days. Lambs were individually weighed in the morning (07:00 h) at the start of experiment and before harvest. Alfalfa hay, DGP and complete mixed diets were subjected to the following analyses: Dry matter (DM, oven drying at $105^{\circ} \mathrm{C}$ until no further weight loss; method 930.15, AOAC 2000); crude protein (CP, $\mathrm{N} \times 6.25$, method 984.13, AOAC 2000); NDF[corrected for NDF-ash, incorporating heat stable $\alpha$-amylase (Ankom Technology, Macedon, NY, USA) at $1 \mathrm{~mL}$ per $100 \mathrm{~mL}$ of NDF solution (Midland Scientific, Omaha, NE, USA), Van Soest et al 1991], ether extract (method 920.39, AOAC 2000), and crude fiber (method 962.09, AOAC 2000). Dry matter content of feed and feed refusal was determined daily. The estimations of dietary energetic and expected DMI were performed based on the estimated initial shrunk body weight (SBW), to convert to a SBW basis is assuming that SBW is $96 \%$ of the full LW and final LW (Cannas et al 2004). Average daily gains (ADG) were computed by subtracting the initial SBW from the final SBW and dividing the result by the number of days on feed. Gain to feed ratio was determined by dividing ADG by the daily DMI. Expected DMI was determined based on observed ADG and average SBW according to the following equation (NRC 1985): expected DMI, $\mathrm{kg} / \mathrm{d}$ $=\left(\mathrm{EM} / \mathrm{NE}_{\mathrm{m}}\right)+\left(\mathrm{EG} / \mathrm{NE}_{\mathrm{g}}\right)$, where EM (energy required for maintenance, $\mathrm{Mcal} / \mathrm{d})=0.056 \times \mathrm{SBW}^{0.75}$ and $\mathrm{EG}$ (energy gain, $\mathrm{Mcal} / \mathrm{d})=0.276 \times \mathrm{ADG} \times \mathrm{SBW}^{0.75}$ estimated accordingly to $\mathrm{NRC}$ (1985), estimated $\mathrm{NE}_{\mathrm{m}}$ (dietary net energy of maintenance) and $\mathrm{NE}_{\mathrm{g}}$ (dietary net energy of gain) are based on the ingredient composition of each experimental diets as described in table 1 . The coefficient $(0.276)$ was estimated assuming a mature weight of $113 \mathrm{~kg}$ for Pelibuey $\times$ Dorper male lambs (Sánchez-Mendoza et al 2016). Observed dietary NE was estimated by of the quadratic formula: $x$ $=\left(-\mathrm{b}-\sqrt{\mathrm{b}^{2}-4 \mathrm{ac}}\right) / 2 \mathrm{c}$, where $x=\mathrm{NE}_{\mathrm{m}}, a=-0.41 \mathrm{EM}, b=$ $0.877 \mathrm{EM}+0.41 \mathrm{DMI}+\mathrm{EG}, c=-0.877 \mathrm{DMI}$, and $\mathrm{NE}_{\mathrm{g}}=$ $0.877 \mathrm{NE}_{\mathrm{m}}-0.41$ (Estrada-Angulo et al 2008). Hot carcass weights (HCW) were obtained for all lambs at the time of slaughter. After carcasses were chilled in a cooler at -2 to $1{ }^{\circ} \mathrm{C}$ for $48 \mathrm{~h}$, measuring of fat thickness (FT) was taken perpendicular to the $\mathrm{m}$. longissimus thoracis, measured over the center of the ribeye between the 12th and 13th rib. All animal management procedures were conducted within the guidelines of of locally approved techniques (Mexican Official Rules, NOM-025, 033 and 051-ZOO-1995) for animal use and care. Performance (DMI, ADG, gain to feed ratio, dietary NE, observed-to-expected dietary NE ratio, observed-to-expected DMI ratio), and carcass data were analysed as a randomised complete block design

Table 1. Composition of experimental diets.

\begin{tabular}{|c|c|c|c|c|}
\hline \multirow{2}{*}{ Item } & \multicolumn{4}{|c|}{ Grape pomace level (\% diet DM) } \\
\hline & 0 & 10 & 20 & 30 \\
\hline \multicolumn{5}{|l|}{ Ingredient composition $(\%)$} \\
\hline Alfalfa hay (mature) & 90.00 & 80.00 & 70.00 & 60.00 \\
\hline Dried grape pomance & 00.00 & 10.00 & 20.00 & 30.00 \\
\hline Ground corn & 6.00 & 6.00 & 6.00 & 6.00 \\
\hline Molasses cane & 3.30 & 3.28 & 3.25 & 3.23 \\
\hline Urea & 0.30 & 0.32 & 0.35 & 0.37 \\
\hline Trace mineral salt ${ }^{1}$ & 0.40 & 0.40 & 0.40 & 0.40 \\
\hline \multicolumn{5}{|c|}{ Chemical composition ${ }^{2}$ (\%DM basis) } \\
\hline Crude protein & 13.95 & 13.88 & 13.88 & 13.86 \\
\hline Ether extract & 1.41 & 1.89 & 2.37 & 2.85 \\
\hline Crude fiber & 43.08 & 43.55 & 43.80 & 44.16 \\
\hline Neutral detergent fiber & 51.94 & 52.07 & 52.72 & 53.44 \\
\hline \multicolumn{5}{|c|}{ Calculated net energy ${ }^{3}(\mathrm{Mcal} / \mathrm{kg})$} \\
\hline Maintenance & 1.14 & 1.11 & 1.09 & 1.06 \\
\hline Gain & 0.59 & 0.56 & 0.55 & 0.52 \\
\hline
\end{tabular}

${ }^{1}$ Mineral premix contained: Calcium, 28\%; Phosphorous, $0.55 \%$; Magnesium, $0.58 \%$; Potassium, $0.65 \%$; NaCl, $15 \%$; vitamin A, 1,100 IU $/ \mathrm{kg}$; vitamin E, $11 \mathrm{UI} / \mathrm{kg}$.

${ }^{2}$ Dietary composition of crude protein, neutral detergent fiber and ether extract were determined by analyzing subsamples collected and composited throughout the experiment. Accuracy was ensured by adequate replication with acceptance of mean values that were within 5\% of each other.

${ }^{3}$ Based on tabular net energy (NE) values for individual feed ingredients (NRC 2007). 
considering lamb as the experimental unit. The MIXED procedure of SAS (2007) was used to analyse the variables. The fixed effect consisted of treatment, and lamb as the random component. Treatment effects were tested for linear, quadratic and cubic components of the DGP supplementation level. Contrasts are considered significant when the $P \leq 0.05$, and tendencies are identified when the $P$-value was $>0.05$ and $\leq 0.10$.

\section{RESULTS AND DISCUSSION}

Chemical composition of alfalfa hay mature and DGP are shown in table 2. Due to differences in chemical composition between alfalfa hay and DGP, the inclusion of DGP slightly increased fiber and lipid concentration of experimental diets (table 1). The chemical composition of alfalfa corresponds closely to those reported by NRC (2007) for alfalfa mature hay. The NE of alfalfa hay used as reference ingredient in our experiment can be estimated from its chemical analyses in our laboratory according to the equation (adapted from NRC (2007), using all fibrous feedstuffs and for which all pertinent analyses are tabulated): $\mathrm{NE}_{\mathrm{m}}, \mathrm{Mcal} / \mathrm{kg}=0.00137 \mathrm{CF} \%+\mathrm{CP} 0.0237 \mathrm{CP} \%+$ $0.0377 \mathrm{EE} \%+\mathrm{NFE} \times 0.0229 \mathrm{NFE} \%)-0.1072, \mathrm{R}^{2}=0.96$, $\mathrm{n}=29$, where $\mathrm{CF}=$ crude fiber, $\mathrm{CP}=$ crude protein, $\mathrm{EE}=$ ether extract and NFE $=100-(\mathrm{CF} \%+\mathrm{CP} \%+\mathrm{EE} \%+\mathrm{ash} \%)$. Accordingly, the estimated EN value of alfalfa hay is 1.06 which corresponds closely to the value of $1.10 \mathrm{Mcal} \mathrm{EN}_{\mathrm{m}}$ ' $\mathrm{kg}$ assigned by NRC (2007). Chemical composition of DGP was consisted with previous reports (NRC 2007, Nistor et al 2014), which is characterised as a source of high fiber content (47-50\%) with moderated concentration of CP (13-15\%) and lipids (5-8\%).

Since there were no quadratic and cubic treatment effects $(P \geq 0.10)$; thus, $P$-values for this component are not presented in the tables.

Treatment effects on growth performance and dietary energetics are shown in table 3. Based on average DMI, supplemental DGP daily intake averaged 0,114, 224 and $372 \mathrm{~g} / \mathrm{lamb}$ (average lamb weight in experiment=22.42 kg).

Table 2. Chemical composition (as percentage of DM) of alfalfa hay (ingredient of reference) and dried grape pomace determined by analyses ${ }^{1}$.

\begin{tabular}{lcc}
\hline Item & Alfalfa hay & $\begin{array}{c}\text { Dried grape } \\
\text { pomace }\end{array}$ \\
\hline Dry matter content & 93.80 & 93.87 \\
Chemical composition & & \\
Crude protein $(\mathrm{N} \times 6.25)$ & 13.43 & 12.64 \\
Ether extract & 1.35 & 5.80 \\
Crude fiber & 45.80 & 49.40 \\
NDF & 42.54 & 43.82 \\
Ash & 7.29 & 7.76 \\
\hline
\end{tabular}

${ }^{1} \mathrm{n}=6$ samples of each ingredient.
The increases of DGP level in diet tended (linear component, $P=0.06$ ) to decrease average daily gain (ADG) and linearly increased $(\mathrm{P}=0.04)$ dry matter intake $(\mathrm{DMI})$; therefore, as replaces of alfalfa hay by DGP increases, feed efficiency, dietary energy, and observed-to-expected diet NE were linearly $(P<0.01)$ decreased, and observed-to-expected DMI was linearly increased $(P<0.01)$. The average observed-to-expected DMI of controls was $101 \%$ of the expected value based on tabular estimates of diet energy density (NRC 2007) and observed SBW and ADG values (table 1), lending support for suitability of the prediction equations proposed by the NRC (1985) for the estimation of DMI in relation to SBW and ADG in feedlot lambs. The linearly increases on DMI on DGP supplemented diets suggest a lower energy (Galyean and Defoor 2003) contained in DGP diets; however, increases of DMI were more pronounced than expected as a result of the estimated energy dilution by growing inclusion of DGP in those diets (table 1). The above is confirmed because the expected-to-observed DMI ratio increased from 1.02 to 1.10 when the level of DGP increased in diet from 10 to $30 \%$. The estimation of dietary net energy and the ratio of observed-to-expected DMI revealed differences on the efficiency of energy utilisation of the diet itself. We expect that observed:expected DMI ratio would be to 1.0 (this mean that animals performed as expected). Or stated differently, animal performance is consistent with DMI and dietary energy density (NRC 2007). If ratio is greater than 1 , the observed DMI represent a lower energy value (concentration) than expected according to NRC (2007), therefore the energy was poorly used by the animal, thus, the efficiency was negatively affected. In contrast, if ratio is less than 1 , energetic efficiency was greater than expected (contrary to the dietary $\mathrm{NE}$ in which values lower than 1 represent greater efficiencies). Based on observed NE (determined through the observed performance of lambs), the comparative $\mathrm{NE}_{\mathrm{m}}$ values of GDP can be estimate using the replacement technique. Given that $\mathrm{NE}_{\mathrm{m}}$ value of mature alfalfa hay is $1.10 \mathrm{Mcal} / \mathrm{kg}$ (NRC 2007), the estimated comparative NE values for the DGP are estimated using the replacement technique (Zinn and Plascencia 1993) as follows: DGP NE $\mathrm{m}_{\mathrm{m}}, \mathrm{Mcal} / \mathrm{kg}=$ [(Test diet NE-Control diet $\mathrm{NE} / \mathrm{DGP} y]+1.10$, where DGP $y$ represents the proportion of DGP that replaced alfalfa hay in the basal diet $(0.10$, 0.20 and 0.30 ), and 1.10 represents de $\mathrm{NE}_{\mathrm{m}}$ of alfalfa hay replaced by DGP. Dietary $\mathrm{NE}_{\mathrm{g}}$ can be derived from $\mathrm{NE}_{\mathrm{m}}$ by the equation $\mathrm{NE}_{\mathrm{g}}=0.877 \mathrm{NE}_{\mathrm{m}}-0.41$ (Zinn et al 2008). Accordingly, the $\mathrm{NE}_{\mathrm{m}}$ and $\mathrm{NE}_{\mathrm{g}}$ values of DGP at the 10, 20 and $30 \%$ inclusion level were 0.80 and $0.29,0.75$ and 0.25 , and 0.67 and $0.18 \mathrm{Mcal} / \mathrm{kg}$, respectively. Those values represent 72,69 , and $63 \%$, respectively, of the relative $\mathrm{NE}$ values of mature alfalfa hay. The average NEm value of DGP at the $10 \%$ inclusion level was identically ( 0.80 $\mathrm{Mcal} / \mathrm{kg}$ ) with the NEm value assigned by NRC (2007) for fermented DGP, and it reasonably agrees with the $0.93 \mathrm{Mcal}$ NEm value determined by difference digestible 
Table 3. Treatment effects on growth performance, dietary energy, and carcass in drylot hairy lambs fed different levels of unfermented dried grape pomace.

\begin{tabular}{|c|c|c|c|c|c|c|}
\hline \multirow{2}{*}{ Item } & \multicolumn{4}{|c|}{ Grape pomace level (\% diet DM) } & \multirow{2}{*}{ SEM } & \multirow{2}{*}{$\frac{P \text {-value }}{\text { Linear }}$} \\
\hline & 0 & 10 & 20 & 30 & & \\
\hline Days on test & 84 & 84 & 84 & 84 & & \\
\hline Replicates & 4 & 4 & 4 & 4 & & \\
\hline \multicolumn{7}{|l|}{ Live weight $^{1}(\mathrm{~kg})$} \\
\hline Initial & 17.64 & 17.85 & 17.74 & 17.97 & 0.35 & 0.58 \\
\hline Final & 27.72 & 27.53 & 26.50 & 26.98 & 0.57 & 0.34 \\
\hline Average daily gain $(\mathrm{kg})$ & 0.120 & 0.115 & 0.104 & 0.107 & 0.004 & 0.06 \\
\hline Dry matter intake (kg/d) & $1.109 \mathrm{a}$ & $1.142 \mathrm{ab}$ & $1.120 \mathrm{a}$ & $1.240 \mathrm{~b}$ & 0.034 & 0.03 \\
\hline Gain to feed $(\mathrm{kg} / \mathrm{kg})$ & $0.108 \mathrm{a}$ & $0.101 \mathrm{ab}$ & $0.093 \mathrm{bc}$ & $0.087 \mathrm{c}$ & 0.004 & $<0.01$ \\
\hline \multicolumn{7}{|l|}{ Observed dietary Net energy (Mcal/kg) } \\
\hline Maintenance & $1.13 \mathrm{a}$ & $1.09 \mathrm{ab}$ & $1.05 \mathrm{bc}$ & $0.99 \mathrm{c}$ & 0.020 & $<0.01$ \\
\hline Gain & $0.57 \mathrm{a}$ & $0.54 \mathrm{ab}$ & $0.51 \mathrm{bc}$ & $0.46 \mathrm{c}$ & 0.018 & $<0.01$ \\
\hline \multicolumn{7}{|l|}{ Observed to expected dietary Net energy ratio } \\
\hline Maintenance & $0.99 \mathrm{a}$ & $0.98 \mathrm{a}$ & $0.96 \mathrm{ab}$ & $0.94 b$ & 0.015 & $<0.01$ \\
\hline Gain & $0.97 \mathrm{a}$ & $0.97 \mathrm{a}$ & $0.93 \mathrm{ab}$ & $0.90 \mathrm{~b}$ & 0.020 & $<0.01$ \\
\hline Observed to expected daily dry matter intake & $1.01 \mathrm{a}$ & $1.02 \mathrm{a}$ & $1.06 \mathrm{ab}$ & $1.10 \mathrm{~b}$ & 0.024 & $<0.01$ \\
\hline \multicolumn{7}{|l|}{ Estimated Net energy of DGP ${ }^{2}(\mathrm{Mcal} / \mathrm{kg})$} \\
\hline Maintenance & & 0.80 & 0.75 & 0.67 & & \\
\hline Gain & & 0.29 & 0.25 & 0.18 & & \\
\hline \multicolumn{7}{|l|}{ Carcass } \\
\hline Hot carcass weight $(\mathrm{kg})$ & 13.58 & 12.98 & 12.57 & 12.82 & 0.37 & 0.14 \\
\hline Dressing percentage & 49.42 & 47.15 & 47.44 & 47.52 & 0.013 & 0.47 \\
\hline Fat thickness $(\mathrm{cm})$ & 0.33 & 0.33 & 0.27 & 0.24 & 0.051 & 0.18 \\
\hline
\end{tabular}

a,b,c Numbers in the same row with different superscript letters differ.

${ }^{1}$ Initial and final live weight (LW) was reduced by $4 \%$ to adjust for the gastrointestinal fill.

${ }^{2}$ Estimated by replacement technique (Zinn and Plascencia 1993).

coefficient of fresh red grape pomace by Baumgärtel et al (2007) and with the energy concentration of $0.87 \mathrm{Mcal}$ $\mathrm{ENL} / \mathrm{kg}$ DM (approximate concentration of 0.95 Mcal of energy of maintenance $/ \mathrm{kg}$ ) of grape marc meal extract determined by digestion trial (Winkler et al 2015). On the other hand, using in vitro gas technique, the NE value of GP have been determined in $0.85 \mathrm{Mcal} / \mathrm{kg}$ (Alipour and Rouzbehan 2007, Besharati et al 2007), but in other study, using the same technique a value of $2.05 \mathrm{Mcal} \mathrm{NEm} / \mathrm{kg}$ was determined (Moghaddam et al 2013).

The increases in observed-to-expected DMI and reductions in dietary NE at high levels of DGP reveal that supplementation at that level had negative effects, independently of its chemical composition; therefore, the reduction of the efficiency on energy utilisation of lambs fed with increasing levels of DGP in this experiment can be due to possible negative effects of DGP on nutrient use, or negative associative effects of DGP on other components of the diet. Based on DGP chemical composition, the estimated NE values of DGP are similar (1.04 Mcal/ $\mathrm{kg}$ ) to the corresponding NE values of the mature alfalfa hay it replaced. However, this value is 30,39 , and $55 \%$ greater, than the NE value estimated for the inclusions levels of 10, 20 and $30 \%$, respectively, obtained from the observed performance of lambs using the replacement technique. The negative associative effects by presence of compound as phenols (not measure in this experiment) could be affected the efficiency on the energy use. Xu et al (2016) reported an average concentration of $102 \mathrm{mg}$ phenolic/kg of red grape pomace, and the anti-nutritional effects of phenolic compounds are well known (Waghorn and McNabb 2003). The above could be supported by previous findings (Bahrami et al 2010, Nistor et al 2016) in which it was observed that intake of DGP increased beyond $10 \%$ while feed efficiency of lambs was notably decreased. On the other hand, Baumgärtel et al (2007) reported a low digestion $(32 \%)$ of organic matter of fresh grape pomace included at level $55.5 \%$ in the diet which contained $29 \%$ concentrates.

Even when a numerically differences were observed between controls vs. high level inclusion of DGP in hot carcass weight $(5.5 \%)$, dressing percentage $(3.8 \%)$, and 
fat thickness (26\%), those differences were not significant $(P \geq 0.14)$.

It is concluded that the estimated NE value of DGP at low level of inclusion in diet (10\%) agrees with the NE value for fermented GDP assigned by the NRC (2007). The increases of inclusion level of DGP beyond $10 \%$ decreases its energy value, maybe due by negative associative effects of chemical compounds (as phenols) naturally contained in DGP. The potential use of this by-product as feed ingredient for lambs would decrease the level of inclusion of high cost forages (such as alfalfa hay), and would contribute to decrease the amount of waste of this material in viticulture industry. However, further studies are needed on the presence of anti-nutritional factors in this by-product in order to have more elements to decide on its inclusion in lamb diets.

\section{REFERENCES}

Alipour D, Rouzbehan Y. 2007. Effects of ensiling grape pomace and addition of polyethylene glycol on in vitro gas production and microbial biomass yield. Anim Feed Sci Technol 137,138-149

AOAC, Association of Official Analytical Chemists. 2000. Official methods of analysis. Association of Official Analytical Chemists, Gaithersburg, Maryland, USA.

Bahrami Y, Foroozandeh AD, Farshad Zamani F, Modarresi M, EghbalSaeid S, et al. 2010. Effect of diet with varying levels of dried grape pomace on dry matter digestibility and growth performance of male lambs. J Anim Plant Sci 6, 605-610.

Baumgärtel T, Kluth H, Epperlein K, Rodehurtskod M. 2007. A note on digestibility and energy value for sheep of different grape pomace. Small Rumin Res 67, 302-306.

Besharati M, Taghizadeh A, Janmohamadi H, Moghaddam GH. 2007. The determination of degradability of grape by-product using in situ and gas production techniques. Iranian Agric Sci 18,173-185.

Bustamante MA, Moral R, Paredes C, Pérez-Espinosa A, MorenoCaselles J, et al. 2008. Agrochemical characterization of the solid by-products and residues from the winery and distillery industry. Waste Manage 28, 372-380.

Cannas A, Tedeschi LO, Fox DG, Pell AN, Van Soest PJ. 2004. A mechanistic model for predicting the nutrient requirements and feed biological values for sheep. J Anim Sci 82, 149-169.
Estrada-Angulo A, Valdés YS, Carrillo-Muro O, Castro-Pérez BI, Barreras A, et al. 2013. Effects of feeding different levels of chromium-enriched live yeast in hairy lambs fed a corn-based diet: Effects on growth performance, dietary energetics, carcass traits and visceral organ mass. Anim Prod Sci 53, 308-315.

Galyean ML, Defoor PJ. 2003. Effects of roughage source and level on intake by feedlot cattle. J Anim Sci 81 (E. Suppl. 2), 8-16.

Manterola BH, Cerda D, Porte EF, Machado C, Shiran LA, et al. 1997. Estudio del comportamiento productivo y variación de parámetros ruminales en novillos alimentados con niveles crecientes de orujo de uva. Avances en Producción Animal 22, 71-80.

Moghaddam M, Taghizadeh A, Nobakht A, Ahmadi A. 2013. Determination of metabolizable energy of grape pomace and raisin vitis leaves using in vitro gas production technique. Anim Prod 15, 40-46.

Nistor E, Dobrei A, Dobrei A, Bampidis V, Ciolac V. 2014. Grape pomace in sheep and dairy cows feeding. J Hortic Forestry Biotech 18, 146-150.

NRC, National Research Council. 1985. Nutrient requirement of sheep. $6^{\text {th }}$ ed. National Academy Press, Washington, D.C., USA

NRC, National Research Council. 2007. Nutrient requirement of small ruminant. Sheep, Goats, Cervids, and New World Camelids. National Academy Press, Washington, D.C., USA

Sánchez-Mendoza B, Aguilar-Hernández A, López-Soto MA, Barreras A, Estrada-Angulo A, et al. 2015.Effects of high-level chromium methionine supplementation in lambs fed a corn-based diet on the carcass characteristics and chemical composition of longissimus muscle. Turkish Vet Anim Sci. 39, 376-379.

SAS, Statistical Analysis System. 2004. SAS version 9.0. SAS Institute Inc., Cary, NC, USA.

Van Soest PJ, Robertson JB, Lewis BA. 1991. Methods for dietary fiber, neutral detergent fiber, and nonstarch polysaccharides in relation to animal nutrition. J Dairy Sci 74, 3583-3597.

Waghorn CC, McNabb WC. 2003. Consequences of plant phenolic compounds for productivity and health of ruminants. Proc Nutr Soc 62, 383-392.

Winkler A, Weber F, Ringseis R, Eder K, Dusel G. 2015. Determination of polyphenol and crude nutrient content and nutrient digestibility of dried and ensiled white and red wine grape pomace cultivars. Arch Anim Nutr 69,187-200.

Xu Y, Burton S, Kim C, Sismour E. 2016. Phenolic compounds, antioxidant, and antibacterial properties of pomace extracts from four Virginia- grown grape varieties. Food Sci Nutr 4, 125-133.

Zinn RA, Plascencia A. 1993. Interaction of whole cotonseed and supplemental fat on digestive function in cattle. J Anim Sci 71, 11-17.

Zinn RA, Barreras A, Owens FN, Plascencia A. 2008. Performance by feedlot steers and heifers: ADG, mature weight, DMI and dietary energetics. J Anim Sci 86, 1-10. 
